\title{
Influence of two different combination of oral contraceptive on some serum electrolytes in women
}

\author{
Sunday O. Ita*, Confidence W. Ihua, Titilope H. Olatunbosun, Mary O. Nteh
}

Department of Physiology, Faculty of Basic Medical Sciences, College of Health Sciences, University of Uyo, Akwa Ibom State, Nigeria

Received: 05 April 2016

Accepted: 07 May 2016

*Correspondence:

Dr. Sunday O. Ita,

E-mail: uloro2003@gmail.com

Copyright: () the author(s), publisher and licensee Medip Academy. This is an open-access article distributed under the terms of the Creative Commons Attribution Non-Commercial License, which permits unrestricted non-commercial use, distribution, and reproduction in any medium, provided the original work is properly cited.

\begin{abstract}
Background: The wide spread use of hormonal contraceptives by women necessitates the assessment of their influence on various biochemical parameters. The objective of this study was to investigate the influence of two different combinations of oral contraceptives on some serum electrolytes in women on oral contraceptives.

Methods: The study involved 50 volunteer female undergraduate students of University of Port Harcourt (20-30 years of age), who were not on contraceptives served as control (group I). Group II consisted of 30 women who were on combined oral contraceptives (methyloestranolone $5 \mathrm{mg}$ and methyloestradiol $0.3 \mathrm{mg}$ ), and group III consisted of 40 women who were on norgesterol-estradiol ( $1 \mathrm{mg}$ and $50 \mu \mathrm{g}$ respectively). These were apparently healthy women attending the Family Planning Unit of the University of Port Harcourt Teaching Hospital who were within the same age group as control.

Results: The combined oral contraceptive therapy (methyloestranolone $5 \mathrm{mg}$ and methyloestradiol $0.3 \mathrm{mg}$ ) in group II significantly reduced serum sodium and chloride ions levels $(\mathrm{p}<0.05)$ while it significantly increased serum potassium and bicarbonate ion levels $(\mathrm{p}<0.05)$ compared with the control group. Low estrogen combined contraceptives; norgesterol-estradiol (group III) significantly reduced sodium and chloride ions compared with the control group $(p<0.05)$ but significantly raised values of these ions higher than those of group II ( $<<0.05)$; whereas it did not alter potassium level significantly compared to group II, low estrogen contraceptives caused significant increase compared to the control group $(\mathrm{p}<0.05)$. Low estrogen combined contraceptives (group III) significantly increased and decreased bicarbonate compared with groups I and II respectively.

Conclusions: The results of this study provide evidence that oral contraceptive, though useful in preventing pregnancies could result in derangement of normal homeostatic processes by interfering with electrolyte balance.
\end{abstract}

Keywords: Oral contraceptive, Serum, Electrolytes, Women

\section{INTRODUCTION}

The combined estrogen/progestin hormonal contraceptive was a breakthrough in contraception for three reasons: because it was highly effective for preventing conception, because, unlike the condom and the diaphragm, the effectiveness of hormonal contraceptives does not depend on its being used in conjunction with the act of intercourse; and because unlike tubal ligation and vasectomy, the effect of hormonal contraceptive is reversible. ${ }^{1}$
Hormonal contraceptives have also been used for their non-contraceptive effects such as in the treatment of dysmenorrhea and menorrhagia and premenstrual syndrome. $^{2-4}$ By preventing ovulation, hormonal contraceptive reduces ultrasound findings of follicular and corpus lacteal cysts. ${ }^{5}$ Combined oral contraceptives confer a 50 percent risk reduction for endometrial cancer and ovarian cancer. ${ }^{6,7}$ The estrogen found in hormonal contraceptives is a strong anti-androgen which is very effective in the treatment of acne. ${ }^{8}$ Hormonal contraceptives are used to correct hormonal disorders in 
women. Hormonal disorders include early menopause, early menstruation, and sometimes, endometriosis., ${ }^{2,8}$

Despite its contraceptive and non-contraceptive uses, the numerous side effects and health risks involving hormonal contraceptive use are manifested in certain body systems such as the cardiovascular system where it gives rise to coronary heart disease, hypertension, stroke, venous thromboembolic disease and obesity. ${ }^{2}$ Other effects include impaired carbohydrate and lipid metabolism, uterine fibrils, liver disorders such as focal nodular hyperplasia, hepatic adenomas and hepatic cellular carcinomas, pancreatitis, headache etc. ${ }^{6}$

In certain studies, it has been shown that hormonal contraceptive could increase cardiac output; this is due to an increase in plasma volume, caused by a hormonal contraceptive induced increase in estrogen. ${ }^{9}$

It is a common side effect of taking an oral contraceptive that woman will experience excess fluid retention and a bloating effect in the kidney, at the distal tubule, progestin acts as a competitive antagonist of the aldosterone receptor. The high contraction or progestin found during the lacteal phase of the menstrual cycle force the body to release excess water and electrolytes resulting in the sudden drop in progestin associated with the transition from the lacteal to follicular phase cause a premenstrual retention of addition of water and electrolytes. However, with this increased water retention comes an increase in body mass and therefore increases in weight. ${ }^{10}$

Studies have shown that certain serious complications occasionally occur which are caused by estrogen containing contraceptives and not caused by the progestin-only formulation, deep vein thrombosis is one example of this. ${ }^{2}$ Using of both hormones together is somewhat more effective than progestin of the serious health hazards associated with hormonal methods of contraceptives. $^{11}$

Electrolyte balance is critical for normal cellular function and maintenance of acid levels, fluid balance impaired muscle functioning. A number of factors can lead to electrolyte imbalance, such as sweating excessively, medical conditions and medications, thus understanding the interactions of the exogenous sex hormones found in hormonal contraceptives and electrolyte balance is crucial.

\section{METHODS}

The study involved 50 volunteer female undergraduate students of University of Port Harcourt (20-30 years of age), who were not on contraceptives served as control (group I). Group II consisted of 30 women who were on combined oral contraceptives (methyloestranolone 5mg and methyloestradiol $0.3 \mathrm{mg}$ ), and group III consisted of 40 women who were on norgesterol-estradiol (1 mg and
$50 \mu \mathrm{g}$ respectively). These were apparently healthy women attending the family planning units of the department of obstetrics and gynaecology, University of Port Harcourt Teaching Hospital who were age-matched with the control group. The subjects were selected after approval from ethics committee of the same hospital.

Blood samples were collected from female subjects using questionnaire as template or guide. Efforts were made to ensure that the subjects conform to the inclusion criteria before mobilizing them for studies.

Blood samples were collected by a vacutainer in the morning into plain sample bottles which were spun with table top centrifuge (RM-12 Micro centrifuge, REMI, England) at $3000 \mathrm{rpm}$ for 10 minutes. Then the serum was separated gently with the help of micropipette and stored in labeled eppendorf tubes at $-20^{\circ} \mathrm{C}$ until assayed for serum chemistry.

\section{Evaluation of serum electrolytes}

TECO diagnostics kit (USA) for sodium was used to determine sodium in the serum. TECO diagnostics kit (USA) for potassium was used to determine potassium in the serum. Agappe diagnostics kit (India) for chloride was used to determine chloride in the serum. TECO diagnostics kit (USA) for determination of carbon dioxide content in the serum. These tests were carried using spectrophotometry.

\section{Statistical analysis}

Statistical analysis was carried out using window SPSS package (SPSS 22 .0 version). Data were analyzed using one way ANOVA followed by post hoc test-least significant difference (LSD). The data were expressed as mean \pm standard error and values of $p<0.05$ were considered significant.

\section{RESULTS}

\section{Sodium ion $(\mathrm{Na}+)$ concentration}

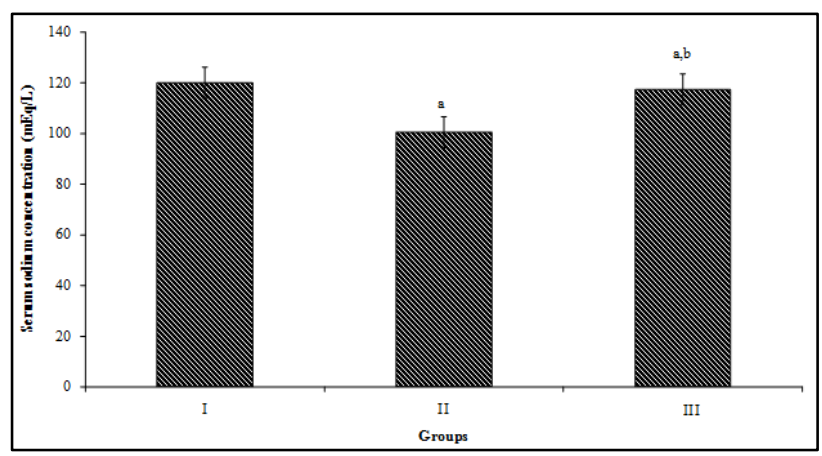

Values are mean \pm SEM, $a=p<0.05$ versus control, $b=p<0.05$ versus group II.

Figure 1: Comparison of serum $\mathrm{Na}+$ concentration for the control and test group. 
The mean value of sodium ion $(\mathrm{mEq} / \mathrm{l})$ concentration obtained were $120.08 \pm 0.20,100.48 \pm 0.26$ and $117.37 \pm 0.23$ for group I (control), group II (estrogen only) and group III (combined contraceptives) respectively. The values obtained for group II and III were significantly lower than the control group $(\mathrm{p}<0.05)$, while the value for group III (combined) was significantly higher than group II (estrogen only) $(\mathrm{p}<0.05)$ (Figure 1).

\section{Potassium ion $(\mathrm{K}+)$ concentration}

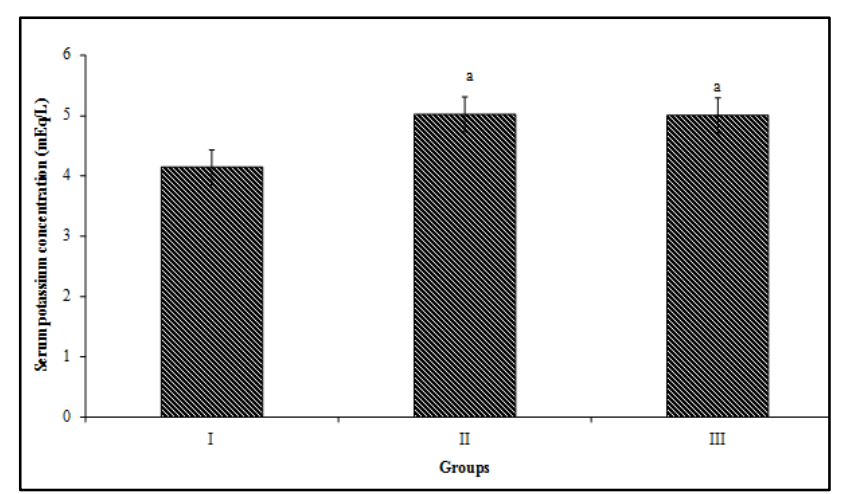

Values are mean \pm SEM, $\mathrm{a}=\mathrm{p}<0.05$ versus control.

Figure 2: Comparison of serum $\mathrm{K}+$ concentration for the control and test group.

The mean value of potassium ion $(\mathrm{mEq} / \mathrm{l})$ concentration obtained were $4.13 \pm 0.04,5.02 \pm 0.02$ and $5.00 \pm 0.04$ for group I, group II and group III respectively. The values obtained for group II and III were significantly higher than the control group $(\mathrm{p}<0.05)$, while the value for group II estrogen was significantly higher than group III (combined) $(\mathrm{p}<0.05)$ (Figure 2).

\section{Chloride ion (Cl-) concentration}

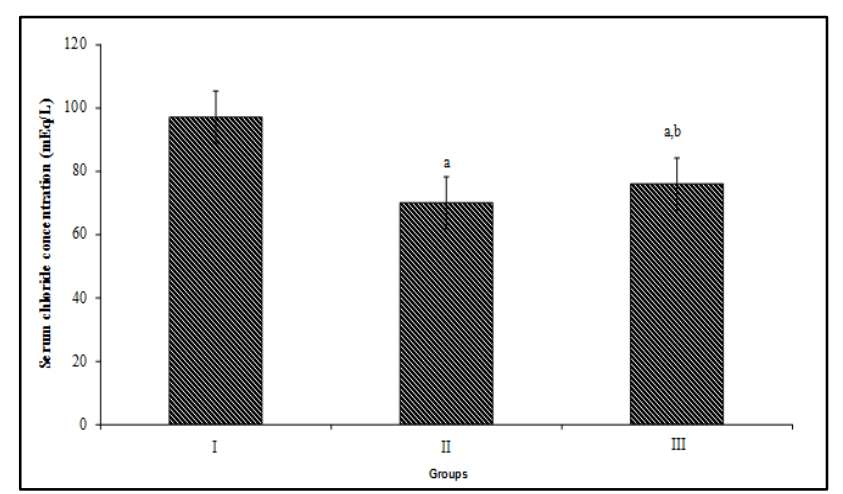

Values are mean \pm SEM, $a=p<0.05$ versus control. $b=p<0.05$ versus group II.

\section{Figure 3: Comparison of serum Cl- concentration for the control and test group.}

The mean value of chloride ion $(\mathrm{mEq} / \mathrm{L})$ concentration obtained were $97.13 \pm 0.28,70.00 \pm 0.20$ and $75.96 \pm 0.25$ for group I, group II and group III respectively. The values obtained for group II and III were significantly lower than the control group $(\mathrm{p}<0.05)$ while the value for group II (combined) was significantly higher than group III (estrogen only) $(\mathrm{p}<0.05)$ (Figure 3$)$.

\section{Bicarbonate ion (HCO3-) concentration}

The mean value of bicarbonate ion (mmol/L) concentration obtained were $24.78 \pm 0.19,27.81 \pm 0.15$ and $25.94 \pm 0.02$ for groups I, group II and group III respectively. The values obtained for group II and III were significantly higher than the control group $(\mathrm{p}<0.05)$ while the value for group II (estrogen only) was significantly higher than group II (combined) $(\mathrm{p}<0.05)$ (Figure 4).

\section{DISCUSSION}

In the present study, treatment with estrogen-only and combined (estrogen and progestin) oral contraceptive led to significant changes in some electrolyte profile. Hormonal contraceptive therapy, be it estrogen alone or combined (estrogen and progestin) led to a significant reduction in $\mathrm{Na}+$ and $\mathrm{Cl}$ - concentration while significantly increasing potassium and bicarbonate concentrations compared with the control group.

This report contradicts the result of, Ghoneim et al, who studied the effect of an oral contraceptive on acid-base balance, blood genes and electrolytes in human females and reported that the oral contraceptive used increased the level of serum sodium. ${ }^{12}$ However, it is known that the hypernatremic effect of hormonal contraceptives may not be noticeable until after 4-5 years of the usual duration of most clinical trials. ${ }^{12,13}$ On the other hand, Akhigbe and his co-workers documented that oral contraceptive (OC) therapy did not alter serum sodium and potassium concentrations significantly. ${ }^{14}$

Some other reports also showed that OC administration affects serum electrolytes. For instance, OC administration has been reported to reduce serum concentration of calcium, magnesium and phosphorus. ${ }^{15}$ Yet, other studies have reported increased plasma concentrations of iron, transferring, zinc and copper. ${ }^{2,16,17}$ Increase body sodium, which is mostly induced by estrogen could exert a stabilizing influence on body water. It is therefore recommended that the prescription of oral contraceptives to patients with cardiac or renal disorders or with hypertension be cautiously undertaken.

It is pertinent to note that both estradiol and progesterone can influence wide spectrum of integrated neural and hormonal mechanisms to regulate electrolytes level in the body, consequently, administration of exogenous estrogen and progesterone in the form of oral contraceptive agents deliver pharmacological levels, which exhibit a far greater estrogenic activity provided by endogenous estrogens. This should of course be of interest as influence of these sex hormones on body fluid 
electrolyte regulation especially sodium has far-reaching implications for a wide range of syndromes for which women are at risk, these include orthostatic hypotension, insulin resistance, polycystic ovary syndrome and exercise-associated hyponatremia. ${ }^{18}$

One most important concept of regulation of body fluid is that regulation of osmolarity must be integrated with regulation of volume, because the body fluids could affect the serum sodium concentrations as reported in this study. This suggests that OC could result in a state of volume depletion, with volume depletion serving as the desired stimulus for the release of antidiuretic hormone $(\mathrm{ADH})$. As a result $\mathrm{ADH}$-stimulated water retention is induced which probably could have caused serum sodium to be diluted resulting in hyponatremia with concurrent hypochloremia reported in this study. Combined estradiol-progesterone administration is reported to cause the greatest increase in plasma volume and maintained extracellular fluid volume; this is probably reported to be due to the combined mechanisms of plasma protein and ECF sodium and fluid maintenance. ${ }^{19,20}$

As stated earlier, ADH plays a role in lowering osmolarity (reducing sodium concentration) by increasing water reabsorption in the kidneys. The fact that OC therapy reduces water consumption as reported by other researchers is a strong enough and reliable reason to hypothesize that it is the desired signal required to induce ADH secretion orchestrated by cellular dehydration for volume expansion, thus the dilution of the osmolarity. ${ }^{14,21-24}$ Although, the combine water retention together with secondary solute loss may result in reduction in serum sodium. ${ }^{25}$ Hyponatremia is mediated initially by $\mathrm{ADH}$-induced water retention that results in volume expansion causing dilution.

Exogenous progesterone (found in combined OC) leads to sodium loss and a compensatory increase in renin secretion, increase plasma rennin activity, angiotensin II secretion and increase in plasma aldosterone. ${ }^{13}$ The compensatory responses as a result of sodium loss causes an increase in the activities of the renin angiotensinaldosterone system (RAAS), thereby leading to increased sodium reabsorption and water retention. Thus, suggesting that the intake of diet with high sodium content during hormonal contraception therapy should be avoided as it may result in hypernatremia increasing risk of development of hypertension.

It is also evidenced in this study, that OC containing only estrogen or in combined form (estrogen and progestin) significantly increased serum potassium concentrations, suggesting that prolonged use of OC could lead to hyperkalemia. Thus continuous use of OC though as beneficial as it is, should be used with caution including avoiding excessive intake of food items with high potassium content including fruits and vegetable like orange. $^{26}$ Also, since oral contraceptives can increase potassium, it could be dangerous or fatal for patients taking other drugs that also may increase potassium, such as angiotensin converting enzyme inhibitors (ACE inhibitors), angiotensin-II receptor agonists, potassiumsparing diuretics, potassium supplementation, heparin, aldosterone antagonists and NSAIDs. OC therapy without caution could be detrimental to health, as many organs including the heart, kidney and the intestine are at risk of damage

\section{CONCLUSION}

The effects of hormonal contraceptives on electrolytes has shown that it exerts severe electrolyte derangement as there were significant reductions in serum sodium and chloride concentrations and elevation in serum potassium and bicarbonate concentration. Thus, indicating a possible distortion of the electrolyte balance and cellular functions by the estrogen and progestin components of hormonal contraceptives. The use of low estrogen content hormonal contraceptives is reported in this study to be somewhat more beneficial considering the health hazards associated particularly with oral contraceptive containing high estrogen content as clearly manifested in the report of this study.

\section{Funding: No funding sources}

Conflict of interest: None declared

Ethical approval: The study was approved by the Institutional Ethics Committee

\section{REFERENCES}

1. Sherman C, Harvey SM, Beckman LJ, Petitti DS. Emergency contraception: knowledge and attitudes of health care providers in a health maintenance organization. Women's Health Issues. 2001;11(5);448 -57.

2. Sheriff K. Benefits and risks of oral contraceptives American Journal of Obstetrics and Gynaecology. 1999;180:343-8.

3. Darney LS, Philip D. A clinical guide for contraception $\left(5^{\text {th }}\right.$ ed). Philadelphia, pa; Lippincott Williams and Wikins; 2010:315.

4. Petitti DB. Crucial practice combination estrogenprogestin oral contraceptives. 2004;350(1):92.

5. Beral BV, Ramcharan SC, Farris RE. Malignant melanoma and oral contraceptive use among women in California. British Journal of cancer. 1977;36(6):804-9.

6. Petitti DB, Porterfield DE. Worldwide variations in the lifetime probability of reproductive cancer in women implication of best-care, worst-case, and likely-care assumptions about the effect of contraceptive use. Contraception. 1992;45(2):93-104.

7. Stephanie BT. Contraception for women with chronic medical conditions: ambivalence toward pregnancy and its effect on contraception. American Journal of obstetrics and Gynaecology. 2009;80(s): 479-83. 
8. Mosher US, Martinez D, Wilson SS. Use of contraception and use of family planning services in United State1982-2002. National Surveys of Family Growth (NSFG). 2002.

9. Goldenberg DP. Computational stimulation of the statistical properties of unfolded proteins. Journal of Molecular Biology. 2003;326:1615-33.

10. Rosenberg M, Meyers AC, Roy VG. Efficacy, cycle control, and side effects of low-and lower-dose oral contraceptives: a randomized trial of $20 \mu \mathrm{g}$ and $35 \mu \mathrm{g}$ estrogen preparations. Contraception. 2000;60:321-7.

11. Lidegaard OJ, Kegaard EB, Anne LS, Carsten AG. Hormonal contraception and risk of venous thromboembolism. Biomedical Journal. 2009;339:628:90.

12. Ghoneim SM, Toppozada HK, El-Henneidy AR, Tana MM. The effect of an oral contraceptive on acid-base balance, blood gases and electrolytes contraception. 1975;12:395-405.

13. Oelkers WK. Effects of estrogen and progesterone on the renin-aldosterone system and blood pressure. Steroids. 1996;61:166-71.

14. Akhigbe RE, Ige SE, Afolabi AO, Oyeyipo PT, Ajao FO, Ajayi FA. Water balance and serum levels of some electrolytes in oral contraceptive treated female Wistar rats. Journal of Medical Sciences. 2008;8:591-4.

15. Simpson GR, Dale K. Serum level of phosphorus, magnesium and calcium in women using contraceptives Fert Sterit. 1972;23:326-30.

16. Eric JS, Baccarini IM, O’Neil HT, Olwin JH. Effects of oral contraceptives on zinc and copper levels in human and endometrium during the menstrual phase. Archives of Gynaecology and Obstetrics. 1979;226:303-6.

17. Hatcher RA, Trussel JE, Stewart FD. Contraception technology. $16^{\text {th }}$ Edition, Irvington Publishers, New York; 1994.
18. Almond CSD, Shin AY, Fortescue EB, Mannix RC, Wypij D, Binstadt BA, et al. Hyponatremia among runners in the Boston Marathon. N Engl J Med. 2005;352:1550-6.

19. Stachenfeld NS, Taylor HS. Effects of estrogen and progesterone administration on extracellular fluid. J Appl Physiol. 2004;96:1011-8.

20. Stachenfeld NS, Taylor HS. Progesterone increase plasma volume independent of estradiol. J Appl Physiol. 2005;98:1991-7.

21. Schwartz SM, Wade GN. Effect of estradiol and progesterone on food intake, body weight and adiposity in weanling rats. American Journal of physiology. 1981;240:E499-E503.

22. Lobo MJ, Remesar XG, Alemany MC. Effect of chronic intravenous injection of steroid hormones on body weight and composition of female rats. Biochemistry and Molecular Biology International. 1993;29:349-58.

23. Ferguson JW, Therapondos A, Newby DE, Hayes PC. Therapeutic role of vasopressin receptor antagonism in patients with liver cirrhosis. Clinical Science. 2003;105:1-8.

24. Wallen WJ, Belanger MP, Wittnich CE. Sex hormones and the selective estrogen receptor modulator for moxifen affect weekly body weight and food intake in adolescent and adult rats. American Society of Nutritional Science. 2001;131: 2351-7.

25. Cooke CR, Turin MD, Walker WG. The syndrome of inappropriate antidiuretic hormone secretion (SIADH): pathophysiologic mechanisms in solute and volume regulation. Medicine. 1979;58:240-51.

26. Berry SE, Mulla UZ, Chowienczk PJ, Sanders TA. Increased potassium intake from fruit and vegetables or supplements does not lower blood pressure or improve vascular functioning UK men and women with early hypertension: a randomized controlled diet. Br J Nutr. 2010;104:1839-47.

Cite this article as: Ita SO, Ihua CW, Olatunbosun TH, Nteh MO. Influence of two different combination of oral contraceptive on some serum electrolytes in women. Int J Reprod Contracept Obstet Gynecol 2016;5:2161-5. 